\title{
Nosocomial infections: What needs to be done?
}

Published at www.cmaj.ca on Aug. 4, 2004.

"At the hospital the ambulance is unloaded and then thoroughly disinfected; the nurse changes her outer clothing, and all blankets are left at the hospital for washing. ... Besides this disinfection at the hospital ... the nurses and officers bathe and change their clothes before they are allowed any leave of absence. There is not much fear, we apprehend, of the station becoming a centre of infection."

$\mathrm{F}$ or most of their history, hospitals were but a refuge for the destitute and dying, places that the wealthy avoided. In the 19th and early part of the 20th century they were used to treat (and contain) infectious diseases such as smallpox (as in the account just cited). But for the past 100 years or so, and especially toward the second half of the last century, hospitals have become a showcase for medicine's miracles and some pretty impressive technology. They are also dangerous places, in part because of the complexity of medical knowledge - multiple drugs and interventions, multiple specialists and multiple, complex systems of care delivery. Mistakes are made, systems break down. ${ }^{2}$

Constant demands for resources to fund new and costly technology strain the budgets of even the best hospital administrators. To operate new scanners or purchase additional stents they must squeeze cash out of core operating budgets. And yet, at the same time, they can't neglect the underlying basic services to patients, or the environmental risks to which patients and staff are daily exposed. The risks are not trivial.

Some nosocomial hazards are carefully monitored and controlled. Staff working with radioactivity wear monitors to continuously scan the environment in which they work. Systems to monitor and red-flag drug doses and interactions are becoming standard in most institutions. Other sophisticated systems using bar codes and product (and patient) microchips are being evaluated to control a variety of potential hazards.

But the monitoring of an expanding array of increasingly resistant microbiological agents is still in the Dark Ages. Patients and staff are not screened routinely for these agents, there are but flimsy reporting procedures; containment, once these infections are in place, is makeshift and constrained by a hospital infrastructure that all too often is a century out of date: multiple patients crowded in single rooms, with but one toilet and a single sink (also used by staff) is the normal set-up in most Canadian hospitals.

SARS was a new organism for which we were unprepared. ${ }^{3}$
But outbreaks of Clostridium difficile, an organism for which there is a highly sensitive and specific test, should not have surprised us. Automated laboratory report systems in most hospitals should have alerted hospital infection control teams and hospital administrators. Public health officials should have been notified. These devastating outbreaks of $C$. difficile have been reported in other countries over the past few years. Last year an expert group in the UK published a comprehensive report on the detection and management of $C$. difficile-associated diarrhea in hospitals, including the recommendation that reporting be mandatory for this organism. ${ }^{4}$

"A wake-up call," we said after SARS. But we slumbered on. The outbreaks of $C$. difficile demonstrate that Canada needs a hospital-based national nosocomial infection surveillance system that functions in real time and is available on the Web to the public, such as the one in the UK. ${ }^{5}$

Refurbishing hospitals and building new ones to meet these new environmental risks is urgent but will take time (and money). While we wait we will also have to cope. The report by Jacques Pépin and colleagues ${ }^{6}$ (see page 466) in this issue suggests that vancomycin may be the drug of choice for treatment of $C$. difficile infection. Because of the high case fatality rate of $C$. difficile-associated diarrhea, and because of the risk of creating vancomycin-resistant organisms, the Canadian Institutes of Health Research (CIHR) should consider releasing emergency funds for this research. To contain these ongoing outbreaks of resistant organisms we need new systems that detect new or unusual rates of infection and provide surveillance information that can be quickly and widely disseminated. — CMAf

\section{References}

1. The new ambulance station of the Metropolitan Asylums Board. BMF 1881;ii:567.

2. Baker GR, Norton PG, Flintoft V, Blais R, Brown A, Cox J, et al. The Canadian Adverse Events Study: the incidence of adverse events among hospital patients in Canada. CMA7 2004;170(11):1678-86.

3. Lessons from SARS [editorial]. CMA7 2003;168(11):1381.

4. National Clostridium difficile Standards Group. National Clostridium difficile Standards Group: report to the Department of Health. 7 Hosp Infect 2004;56 Suppl 1:1-38. Standards available at www.dh.gov.uk/assetRoot/04/06/76/51 /04067651.pdf (accessed 2004 Aug 3).

5. Department of Health Mandatory Bacteraemia Surveillance Scheme: NHS Trust: April 2001-2004. Available: www.dh.gov.uk/assetRoot/04/08/58/93 /04085893.pdf (accessed 2004 July 28).

6. Pépin J, Valiquette L, Alary ME, Villemure P, Pelletier A, Forget K, et al Clostridium difficile-associated diarrhea in a region of Quebec from 1991 to 2003: a changing pattern of disease severity. CMAJ 2004;171(5):466-72. Epub 2004 Aug 4 (DOI:10.1503/cmaj.1041104). 